\title{
O cálculo de perímetro e de área de figuras planas: dificuldades encontradas pelos alunos da EJA
}

Taiane de Oliveira Rocha

Jonson Ney Dias da Silva

\section{Resumo}

O presente artigo tem por objetivo apresentar uma investigação cujo objetivo principal foi identificar as dificuldades que os alunos da Educação de Jovens e Adultos (EJA) possuem no estudo do cálculo de perímetro e de área de figuras planas. Para isso, foi utilizada uma abordagem de caráter qualitativa. A produção dos dados ocorreu em um colégio estadual na cidade de Vitória da Conquista - Bahia, por meio de atividade diagnóstica, aplicação de oficina e entrevistas com o professor e aluno. Após a análise, foram identificadas quatro dificuldades na aprendizagem dos alunos: interpretação dos enunciados; cálculo das quatro operações fundamentais; operações com os números racionais e decimais; nomeação e explicação sobre as características das figuras geométricas incorretamente. Tal pesquisa visa a contribuição da discussão acerca da temática da EJA e o ensino de matemática e de geometria entre os professores, além de subsidiar outras pesquisas.

Palavras-chave: Ensino de Geometria; EJA; Dificuldades de aprendizagem. 


\title{
The calculation of perimeter and area of plane figures: difficulties found by the students of the EJA
}

\author{
Taiane de Oliveira Rocha \\ Jonson Ney Dias da Silva
}

\begin{abstract}
\end{abstract}
This article aims to present an investigation that has as its main objective identifying the difficulties that Youth and Adult Education (EYA) students have in calculate the perimeter and area of plane figures. Thus, a qualitative approach was used. The data were collected in a state School in the city of Vitória da Conquista, state of Bahia, by the use of diagnostic activity, with workshops and interviews with teachers and students. After the analysis, four factors of difficulties were identified: statement questions interpretation; calculation of the four mathematical operations; rational and decimal numbers operations; designation and explanation of the geometric figures characteristics incorrectly described. The object of this research is the contribution of the EJA thematic and the math and geometry teaching discussion among teachers, and also subsidize other studies.

Keywords: Geometry Teaching; EJA; Learning difficulties 


\section{Introdução}

A Educação de Jovens e Adultos (EJA) passou a ganhar espaço no Brasil a partir da década de 1930. Anteriormente, ela tinha o objetivo apenas de erradicar o analfabetismo; posteriormente, ganhou um espaço na sociedade. Desde então, vários projetos e leis foram elaborados com o intuito de tornar a EJA em uma modalidade de ensino. Após a lei $n^{\circ} 9394$ de 20 de dezembro de 1996, houve a garantia da educação gratuita para os alunos jovens e adultos que por algum motivo deixaram de estudar.

O público da EJA é diversificado devido a vivências, experiências, faixas etárias, cultura, dentre outros fatores. Geralmente é um aluno que trabalha e, do próprio trabalho, vai à escola. Percebe-se, atualmente, o aumento de jovens que ingressam na EJA. Na maioria dos casos, devido à necessidade de trabalhar muito cedo ou ao fato de ter repetido muitos anos a mesma série, a uma gravidez indesejada, ou por causa do tempo de conclusão; e, como boa parte das aulas de EJA, é o período noturno que permite ao aluno trabalhar e estudar.

No ensino de matemática na EJA, é importante relacionar o conteúdo matemático com atividades cotidianas com o intuito de aproximar a realidade do aluno; além disso, deve partir dos conhecimentos prévios dos alunos. Cabe ao professor articular esses conhecimentos com novos conhecimentos, estimulando a aprendizagem dos alunos. Isso porque muitos veem a matemática como difícil e, muitas vezes, difícil de aprender e por esse motivo, acabam "bloqueando" a aprendizagem dos conteúdos.

Em relação ao ensino de geometria, até a década de 1960, vários livros didáticos abordavam a geometria euclidiana como algo verdadeiro e que não podia ser questionado, ele era baseado na obra "Os elementos" de Euclides. Depois disso, houve a influência do Movimento da Matemática Moderna cujo foco era a linguagem; não se atentavam à aprendizagem dos conceitos. Nessa época, os conteúdos geométricos eram apresentados ao final do livro, o que gerou o abandono do ensino de geometria nas escolas.

Depois de alguns anos, os livros didáticos foram reestruturados, e o conteúdo de geometria passou a ser distribuído no início, no meio e no fim do livro. Todavia, mesmo com essa mudança, em algumas escolas, percebe-se que ainda há a omissão do ensino de geometria, tanto no ensino regular quanto na EJA. As causas são variadas: falta de conhecimento do professor devido à formação acadêmica, pouco tempo de aula destinada à disciplina de matemática, insegurança do professor em ensinar a geometria, dentre outras (SANTOS, NACARATO; 2014).

Percebe-se, então, que também há falhas e até mesmo omissão do ensino de geometria na EJA. Por isso, foi realizada uma pesquisa para explorar o conhecimento, a aprendizagem e as dificuldades encontradas por esses alunos da EJA no cálculo de perímetro e de área das figuras planas. O motivo de escolher o perímetro e a área das figuras planas foi devido à 
possibilidade de associação desse conteúdo com a realidade e o cotidiano vivenciado por alguns alunos da EJA, incentivando, desse modo, a aprendizagem do conteúdo.

O propósito dessa pesquisa foi identificar as dificuldades que os alunos da EJA possuem na aprendizagem do cálculo de área e de perímetro das figuras planas, e, a partir daí, observar como os alunos conseguem compreendê-lo. Para isso, foi utilizada uma abordagem qualitativa, na qual a produção dos dados foi realizada por meio de atividade diagnóstica, oficina e entrevistas individuais com o professor e com alguns alunos. A questão que norteou essa pesquisa foi "Quais as dificuldades que os alunos da Educação de Jovens e Adultos possuem na aprendizagem dos conteúdos geométricos, como o cálculo de perímetro e de área de figuras planas?”.

Desse modo, esse artigo apresenta uma breve discussão sobre a EJA e o ensino de geometria. Em seguida, a abordagem metodológica utilizada, a análise dos dados e, por fim, as considerações finais.

\section{A Educação de Jovens e Adultos: lei, alunos e currículo}

A Educação de Jovens e Adultos - EJA é considerada uma modalidade de ensino, cujo objetivo é inserir jovens, adultos e idosos que não tiveram acesso à escola na idade própria ou que, por algum motivo, deixaram de estudar e querem retornar e, assim, concluir sua formação escolar. A Lei No 9.394 de 20 de dezembro de 1996 garante aos jovens, adultos e idosos educação gratuita e oportunidades de estudos, levando em consideração o perfil do aluno da EJA: um trabalhador que necessita do trabalho para sua sobrevivência (BRASIL, 1996).

As turmas de EJA são constituídas por pessoas de experiências de vida, valores, culturas, faixas etárias e visões de mundo distintas. Na maioria das vezes, esses alunos, retornam à escola devido a exigências no trabalho, na tentativa de buscar uma melhor condição de vida e outros por vontade de aprender novos conhecimentos. De acordo com Brasil (2001), o currículo da EJA deve ser diferenciado, no intuito de atender às necessidades desses alunos, isso por causa da heterogeneidade e das vivências.

Segundo Brasil (2001), o currículo da EJA não é fixo e estático, pelo contrário, deve ser adaptado de acordo com o nível de conhecimento e das necessidades dos alunos. Por isso, cabe ao professor, pensar estratégias que trabalhem a diversidade e a autonomia, para, assim, estimular o pensamento e a aprendizagem dos alunos. Também, cabe à escola promover atividades de interação, como, por exemplo, gincanas e exposições, nas quais os alunos sejam provocados a discutir, dialogar, investigar e buscar a autonomia em solucionar problemas.

\section{O ensino de Matemática na Educação de Jovens e Adultos}

Desse modo, o estudo da Matemática na EJA baseia-se em estratégias para a resolução de problemas, na utilização do conhecimento prévio dos alunos e no estímulo da 
criatividade, do diálogo e do trabalho em grupo, pois este é rico em experiências tanto individuais quanto coletivas, e, juntos, possibilitam a construção de novos conhecimentos (FONSECA, 2011). Além disso, é baseado nos desafios que reforçam a capacidade de raciocinar e a autonomia para buscar recursos que contribuem para a aprendizagem.

De acordo com a proposta curricular da EJA (BRASIL, 2002), o ensino de matemática deve valorizar a cultura e permitir ao aluno transformar o ambiente em que vive por meio de sua participação no mundo do trabalho, e, com isso, relacionar-se socialmente com a política e a cultura. Por isso, o currículo da EJA não deve ser baseado em memorizações e regras, mas na utilização de métodos facilitadores para o entendimento relacionando matemática e cotidiano.

\section{Ensino de geometria na Educação de Jovens e Adultos}

Neste contexto, a Geometria é um conteúdo de extrema importância para o desenvolvimento do raciocínio na vida cotidiana. Desse modo, Fonseca (2009) aponta a importância dos valores culturais para a compreensão de conceitos da matemática, como, por exemplo, a apreciação de obras de arte, da natureza e do homem. A partir dessas considerações de Fonseca, percebe-se que o estudo geométrico, a partir dessas apreciações, gera uma capacidade potencial para a formação humana, além da compreensão dos conceitos de geometria.

Apesar dessa importância do estudo da geometria, em algumas escolas não há disciplina para a geometria e ela não é estudada na disciplina de matemática. De acordo com Lorezanto (1995), Pavanelo (1993) e Santos e Nacarato (2014), isso ocorre devido à organização do livro didático, que antes apresentava os conteúdos geométricos ao final do livro, e assim, era estudado ao fim do ano se houvesse tempo, e, além disso, muitos professores utilizam-no como recurso único para planejar as aulas.

Atualmente, os livros didáticos foram reformulados e apresentam os conteúdos geométricos no início, no meio e no fim; porém, mesmo assim, os conteúdos, na maioria das vezes, não são ensinados. Na EJA ocorre do mesmo modo que no ensino regular, o livro didático de Scrivano (2013), por exemplo, apresenta o conteúdo de geometria distribuído por todo o livro. No entanto, na maioria das vezes, o professor não insere os conteúdos no plano de curso de matemática.

Segundo Santos e Nacarato (2014), a falta de conhecimento do professor devido à formação acadêmica interfere na preparação da aula. Isso porque, devido ao fato de não ter estudado o conteúdo, possui insegurança em ensinar a geometria.

De acordo com a proposta curricular da EJA (BRASIL, 2001; BRASIL, 2002), em relação à aprendizagem das formas geométricas, as primeiras atividades desenvolvidas serão de observação e reconhecimento dessas formas nos objetos do ambiente. Em seguida, deve-se 
realizar atividades de situações-problema, para, assim, efetuar cálculos a fim de encontrar o perímetro e a área de figuras geométricas, além de realizar comparações sobre as áreas de diferentes figuras.

Almeida e Costacurta (2010) e Santos e Nacarato (2014) relacionam o ensino de Geometria com atividades cotidianas, como, por exemplo, o trajeto realizado da casa até escola, a construção de uma casa. Podemos considerar que na EJA também é importante utilizar o conhecimento prévio dos alunos, trazidos do cotidiano e da vivência. Assim, ao trazer essa sabedoria é possível associar diversos contextos do dia a dia com a Geometria. Isso porque muitos alunos da EJA são trabalhadores, alguns comerciantes, outros pedreiros, e são profissões que estão extremamente relacionadas com os conteúdos matemáticos e geométricos.

Sendo assim, um dos conteúdos geométricos que pode estar relacionado com o cotidiano dos alunos é o cálculo de perímetro e área de figuras planas. Para estudar sobre a área e o perímetro de um objeto, inicialmente compreende-se a noção de espaço e forma. Pois, para calcular a área de um quadrado, por exemplo, primeiro é preciso diferenciar um quadrado de um triângulo, quais as suas propriedades que definem esses objetos, para, a partir daí, efetuar o cálculo. Fonseca (2009) aponta a importância da compreensão dos conceitos de grandezas e medidas para a associação das propriedades relativas às formas das figuras geométricas.

Por esse motivo, resolveu-se observar como a Geometria é trabalhada nessa modalidade de ensino e quais as dificuldades que os alunos possuem no processo de trabalhar este conteúdo. Diante disso, o presente estudo tentou identificar as dificuldades que os alunos da EJA possuem ao trabalhar com o cálculo de perímetro e de áreas das figuras planas.

\section{Metodologia}

O foco principal desta pesquisa constituiu-se em entender e perceber as dificuldades que os alunos da EJA encontram no processo de aprendizagem do cálculo do perímetro e da área das figuras planas. Por esse motivo, foi escolhida uma abordagem qualitativa que, de acordo com Bodgan e Biklen (1994), o pesquisador tem um contato direto com o ambiente a ser pesquisado, que, neste caso, é uma turma da EJA.

Sendo assim, o tipo de pesquisa qualitativa foi a de campo, pois, a partir dela, a produção dos dados ocorre no ambiente no qual se encontra o problema e pode ser através de entrevista, amostragem, questionário, observação participante, entre outros. (FIORENTINI, LORENZATO; 2009). Isso porque, para responder à pergunta diretriz da pesquisa, é necessária a presença do pesquisador na escola para realizar as atividades com os alunos e identificar as dificuldades encontradas por eles. 
Portanto, a atividade diagnóstica, a aplicação de oficina e a entrevista foram os instrumentos utilizados para a produção dos dados. Isso porque os dados da pesquisa precisam ser descritos para identificar as dificuldades e a aprendizagem. Segundo Fiorentini e Lorenzato (2009), os questionários (no caso dessa pesquisa, a atividade diagnóstica) são utilizados na fase inicial e exploratória da pesquisa com o intuito de identificar informações prévias e pessoais. Ou seja, a atividade diagnóstica tem por objetivo identificar os conhecimentos prévios dos alunos em relação às figuras planas.

As entrevistas têm a importância de os sujeitos falarem o que estão pensando naquele momento, sua opinião, seus pontos de vista sobre o assunto abordado. (BODGAN, BIKLEN; 1994). No caso dessa pesquisa, a entrevista tem o intuito de comparar as dificuldades observadas pelo pesquisador e as apontadas pelos alunos, e com isso, chegar a uma conclusão final das dificuldades encontradas.

\section{Contexto}

A pesquisa foi realizada com uma turma de EJA no Colégio Estadual, situado na Cidade de Vitória da Conquista. A turma que participou da pesquisa foi o eixo VII do Tempo Formativo III, cujo objetivo é tornar a aprendizagem dos alunos o mais próximo da realidade, além de atender suas necessidades na busca de diminuir a evasão escolar. O Tempo Formativo III é referente ao Ensino Médio, com duração de 2 anos. O eixo VII dura um ano e trabalha com as disciplinas exatas envolvendo os conteúdos de $1^{\circ}, 2^{\circ}$ e $3^{\circ}$ anos do Ensino Médio.

O referido colégio existe desde 2002. No ano da pesquisa possuía 24 turmas com aproximadamente 900 matriculados, sendo 320 no turno matutino, 300 no turno vespertino e 280 no turno noturno. No turno matutino e vespertino estão presentes o ensino fundamental II e o ensino médio. Somente no turno noturno que há o ensino fundamental II, o ensino médio e a EJA.

A modalidade EJA está presente na escola desde 2002, quando a escola foi fundada. São 5 turmas de EJA com uma média de 35 alunos em cada turma. Vale destacar, que a escola realiza anualmente um "Projeto da Semana do Trabalho" para os alunos da EJA. Esse tema é devido ao perfil do aluno da EJA da escola: alunos que trabalham em tempo integral. Neste projeto, a escola realiza oficinas, discussões sobre o mundo do trabalho e traz pessoas para falar sobre cursos profissionalizantes, com o intuito de motivar a formação desses alunos.

O professor regente da turma do eixo VII começou a trabalhar neste colégio no ano de 2002 e, desde o início, sempre trabalhou com a EJA. Sobre a turma escolhida, as idades dos alunos variam entre 18 e 40 anos, aproximadamente. São 43 matriculados, mas a frequência fica entre 12 a 20 alunos. 


\section{Desenvolvimento da produção de dados}

Para a realização da pesquisa, foi feita uma produção de dados que durou 3 meses. A primeira parte da proposta de produção de dados foi composta por uma atividade de identificação de figuras planas, com o intuito de fazer um diagnóstico sobre o conhecimento prévio dos alunos em relação às figuras geométricas. Isso porque os alunos participantes da pesquisa ainda não haviam estudado conteúdos referentes à Geometria e, para a oficina, era necessário o conhecimento de alguns conteúdos. Desse modo, foi realizada, no primeiro momento, atividade diagnóstica, no segundo, oficina e, no terceiro, entrevista com alunos e professores.

A atividade diagnóstica possuía duas questões: uma sobre identificação das figuras utilizando lápis de cor, cujo objetivo era verificar se os alunos conheciam as figuras geométricas, por exemplo, com a cor verde deveriam pintar as figuras que eles nomeavam como triângulos; uma questão discursiva, na qual o aluno deveria explicar como conseguiu identificar as figuras, o objetivo dessa questão foi estimular os alunos a escreverem o que estavam pensando, anotar as informações que eles tinham sobre as figuras e as características observadas.

Após o término da atividade diagnóstica, foi estruturada uma oficina a fim de verificar as dificuldades que os alunos encontraram no processo de aprendizagem do cálculo de perímetro e de área das figuras planas. A oficina possuía questões que, utilizando o Geoplano como instrumento, desenvolviam o raciocínio, a dedução das fórmulas e o cálculo do perímetro e da área das figuras planas. Inicialmente o professor explicava o que deveria ser feito na atividade, depois os alunos praticavam no Geoplano e desenvolviam o raciocínio para a elaboração da fórmula geral. Esta metodologia seguiu para as demais questões.

A distribuição da carga horária para a oficina foi 2 horas/aula de planejamento entre professor regente e pesquisadora. Foram destinadas 2 horas/aula para a interação da oficina entre pesquisadora e professor regente, já que o professor que iria aplicar a oficina e a pesquisadora ficaria em observação da aula. Inicialmente foram propostas 8 horas de oficina, acerca do cálculo de perímetro e de área das figuras planas. Com o decorrer das aulas, houve a necessidade de adicionar mais 4 horas de observação da realização da avaliação sobre o conteúdo abordado.

Após a oficina e a análise das atividades abordadas, foi realizada uma entrevista com alguns alunos que estavam presente no dia destinada a entrevista e com o professor, com a finalidade de subsidiar os questionamentos constatados durante a atividade diagnóstica e a oficina. A seguir, falaremos um pouco sobre as dificuldades encontradas na produção dos dados: atividade diagnóstica e na oficina, articuladas com algumas informações da entrevista. 


\section{Análise dos resultados e discussão}

A atividade diagnóstica foi elaborada porque os alunos não haviam estudado nenhum conteúdo de geometria no ano em que a pesquisa foi realizada. Então a proposta era identificar os conhecimentos prévios que os alunos possuíam em relação às figuras geométricas. Pois, para estudar o perímetro e a área das figuras planas é importante que haja uma explicação anterior sobre as propriedades de cada figura para facilitar e auxiliar na compreensão.

Os objetivos das atividades da oficina, para os alunos, incluem o desenvolvimento do raciocínio lógico, da criatividade e da capacidade de resolver problemas aplicando o método de investigação matemática; além de promover o uso de recursos didáticos no estudo da geometria como auxílio na aprendizagem dos conceitos. Outro objetivo é a utilização do Geoplano como um recurso que auxilie no estudo da Matemática de forma lúdica, em uma abordagem dinâmica e interativa.

Essas atividades foram desenvolvidas em duplas, e os estudantes tiveram em mãos um Geoplano e um conjunto de elásticos. Almeida e Costacurta (2010) afirmam que é importante utilizar recursos diferenciados e materiais manipulativos em sala de aula, pois estes contribuem para o raciocínio lógico e visual do aluno. Deste modo, a utilização da ferramenta Geoplano foi um recurso auxiliador na aprendizagem e no entendimento do conteúdo.

Durante a oficina, os alunos estavam motivados e interessados em resolver os problemas, para, assim, encontrar a fórmula de cálculo do perímetro e da área das figuras planas. Para o cálculo do perímetro, eles não tiveram muita dificuldade. Desenvolveram a ideia de que o perímetro é a soma dos lados de qualquer figura. A partir dessa ideia, conseguiram calcular o perímetro de todas as figuras.

Já o cálculo da área foi mais trabalhoso, porque os alunos deveriam construir a figura geométrica no Geoplano e calcular a sua área, depois construírem a mesma figura com um tamanho maior e calcularem novamente. A última etapa era para encontrar um método (fórmula) que calculasse a área dessa figura com qualquer tamanho e sem a utilização do Geoplano. Desse modo, conforme realizavam a construção, os alunos deveriam anotar todo o desenvolvimento realizado, registrando o passo a passo do seu pensamento e da construção da fórmula geral.

\section{Dificuldades encontradas após a análise}

\section{Primeira dificuldade: interpretação dos enunciados}

Alguns alunos apresentavam dificuldade em interpretar as questões e problemas, e, isso foi visto durante a atividade diagnóstica quando os alunos deveriam ler e interpretar o que estava escrito na questão 2 da atividade, conforme a figura 1, e também nas questões da oficina. 
Figura1. Questão 2 da atividade diagnóstica

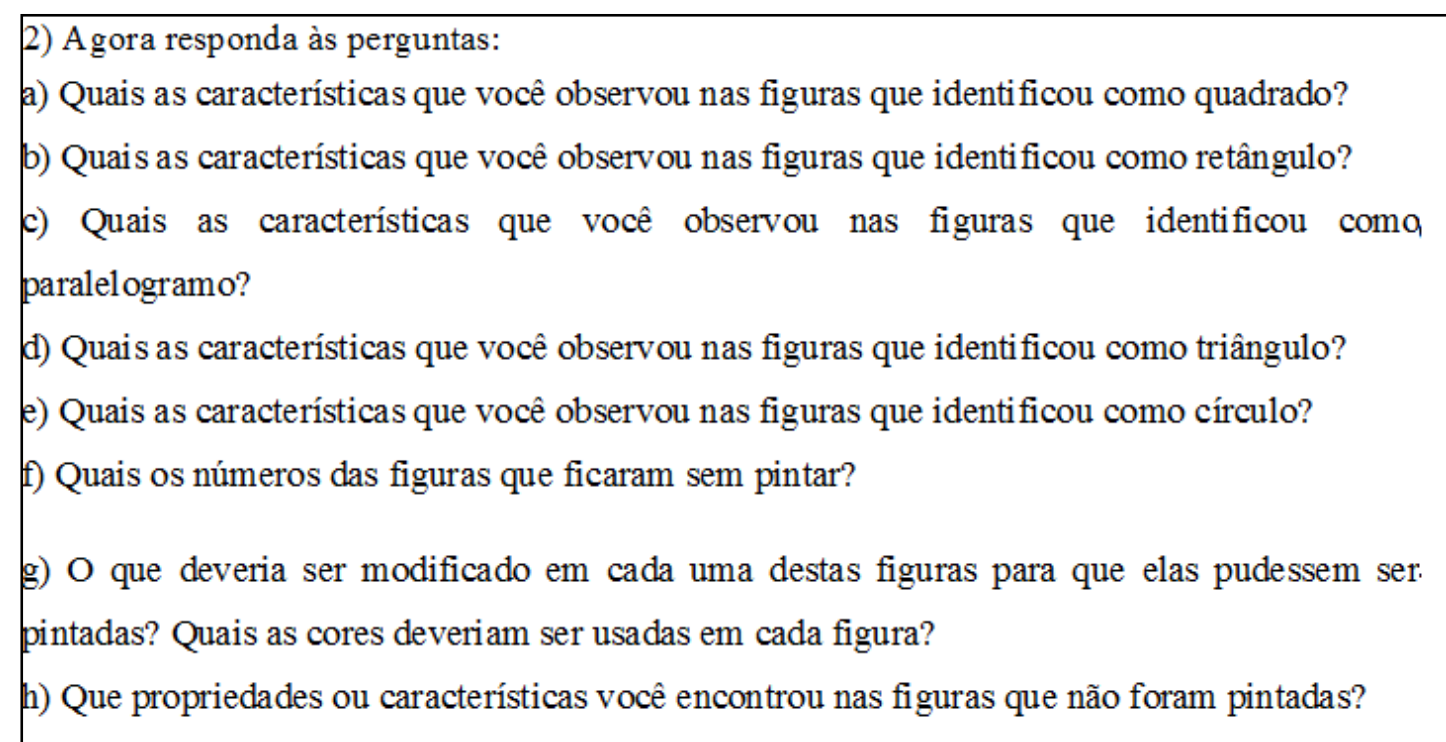

Fonte: Documentos da pesquisa

Durante a leitura do enunciado das perguntas, alguns alunos não conseguiam compreender o que era solicitado na questão e, por isso motivo, pediam para que fosse realizada a leitura pela pesquisadora, em voz alta. Alguns conseguiram entender e, em seguida, escreveram as características identificadas; para outro será preciso que a pergunta fosse explicada com outras palavras, como por exemplo, "Para você, porque essa figura é um quadrado?”. A partir dessa explicação conseguiram responder as outras alternativas da questão 2.

Após as observações realizadas, considera-se que o motivo que pode ter provocado a falta de compreensão dos enunciados pelos alunos, pode ser devido às aulas de matemática possuírem problemas e, também, a enunciados que não fazem o aluno pensar e refletir, pois, na maioria das vezes, eles estão habituados a resolver problemas matemáticos mecanicamente, utilizando a calculadora ou fazendo o cálculo mental.

Essa dificuldade em interpretar problemas também foi apontada pelo professor da turma durante a entrevista. Segundo ele, "os alunos têm a dificuldade em interpretar não ocorre somente na disciplina de matemática, mas também nas outras disciplinas”.

\section{Segunda dificuldade: cálculo das quatro operações fundamentais}

As questões da oficina foram referentes ao cálculo de perímetro e de área das figuras planas. Os alunos conseguiram compreender a forma de resolução, além de elaborarem uma fórmula para que fosse possível calcular o perímetro ou a área de uma figura com qualquer tamanho, porém apresentaram dificuldades em relação ao cálculo das quatro operações, situação apontada pelo professor durante a entrevista. 
Além disso, possuíram dificuldade no cálculo mental e escrito das quatro operações fundamentais, como por exemplo, soma simples como 2+2. Poucos possuíam o raciocínio rápido e realizavam o cálculo mentalmente, outros utilizavam a calculadora e, mesmo assim, não conseguiam fazer a formalização escrita dos cálculos, ou seja, quando era solicitado que realizassem os cálculos no papel, alguns utilizavam a calculadora do celular, outros calculavam contando os dedos das mãos, e outros não queriam fazer a atividade porque havia muitos cálculos.

Durante o cálculo da área das figuras, um aluno, somou a quantidade de quadrados que tinha dentro do Geoplano. Por exemplo, a área de um quadrado de lado $2 \mathrm{u}$ seria igual a $4 \mathrm{u}$, pois, dentro da construção do quadrado formado, possuía quatro quadrados menores, como pode ser visto na figura 2.

Figura 2. Construção de um quadrado no Geoplano

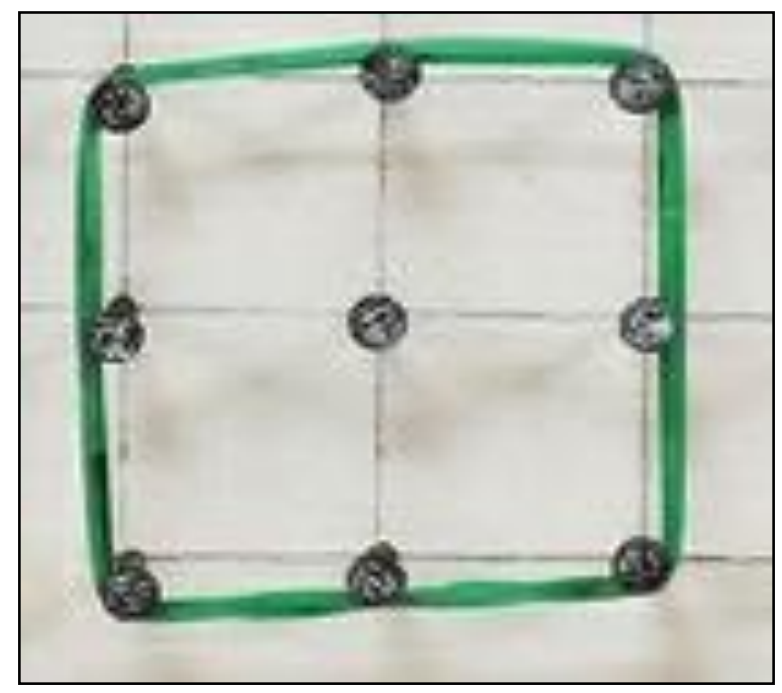

Fonte: Documentos da pesquisa

Depois disso, foi solicitado a esses alunos que fizessem o cálculo da área de um quadrado que tivesse lado $3 \mathrm{u}$. A resposta dele foi $9 \mathrm{u}$, pois tinha nove quadrados menores. Nesse momento o aluno foi questionado "e se eu tiver um quadrado de lado 10u, como eu calculo a área?”. O aluno respondeu que não sabia como responder, porque não dava para construir no Geoplano. Em seguida, foi perguntado para ele, como calcular a área de quadrado qualquer sem utilização do material manipulável. Ele disse que seria multiplicando, porém não sabia como efetuar a multiplicação. Após isso, foi feita uma explicação para esse aluno sobre a multiplicação entre dois números.

Com isso, percebe-se que havia dificuldades tanto na adição quanto na multiplicação. A subtração e a divisão não foram trabalhadas nessas atividades. 


\section{Terceira dificuldade: operações com números decimais e racionais}

$\mathrm{Na}$ atividade sobre o cálculo de perímetro e de área do paralelogramo, foi encontrada outra dificuldade: soma e multiplicação de números inteiros com números decimais. Isso porque, ao construir o paralelogramo no Geoplano, dois lados passavam por cima da diagonal do quadrado, por esse motivo, a diagonal resultava na medida $\sqrt{2}$. Alguns alunos nunca haviam visto o número $\sqrt{2}$ e outros disseram não saber calcular com esse número, e, com isso, percebeu-se que os alunos tinham dificuldades em realizar cálculos com números racionais. Para facilitar os cálculos, o professor fez a aproximação do número racional $\sqrt{2}$ para o número decimal 1,4 .

Ao observar a soma realizada pelos alunos, o resultado da soma $1+1+1,4+1,4$ era igual a 3,o como pode-se observar na figura 3. Eles somavam o número um com o número quatro, para eles $1 \neq 1,0$. Depois disso, o professor explicou para eles como realizar o cálculo utilizando os números inteiros e decimais. Durante a entrevista, o professor comentou que geralmente os números que ele coloca nas atividades são números inteiros. Isso porque os alunos já possuem dificuldades em realizar os cálculos com os números inteiros e com os números decimais, a dificuldade é maior ainda.

Figura 3. Cálculo com número decimal apresentado por um aluno

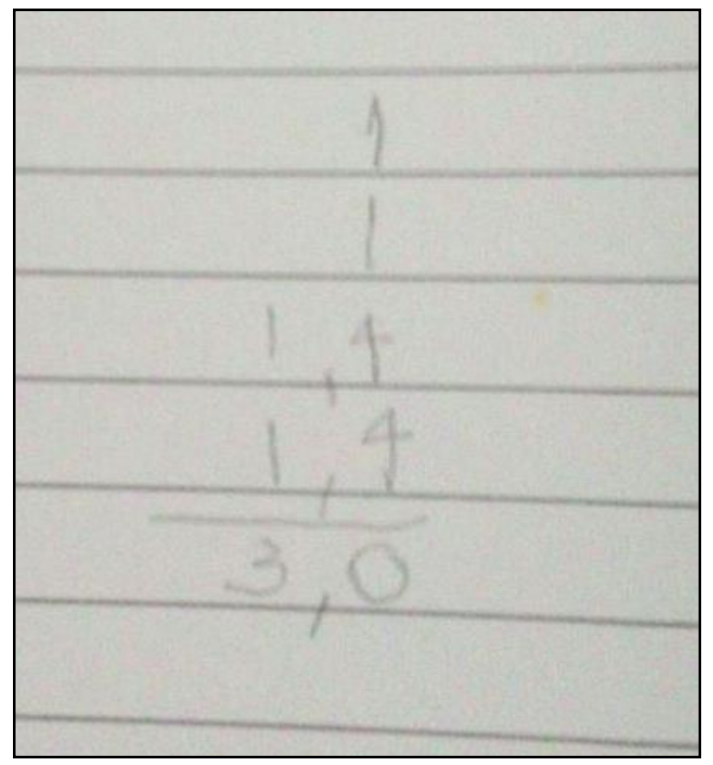

Fonte: Documentos da pesquisa

Para calcular a área do paralelogramo, os alunos criaram um método denominado por eles de "método do roubo". Eles construíam o paralelogramo no Geoplano, depois tentavam completar as partes que estavam faltando para formar um quadrado ou retângulo, ou seja, construíam, ao lado do paralelogramo, um quadrado que obtivesse as mesmas medidas daquele, e, assim, calculavam as áreas desejadas, a partir do cálculo da área do quadrado. Isso 
quer dizer que os alunos tentavam transformar a figura em outra que eles já conheciam o método para realizar os cálculos.

Um aluno fez uma comparação com o dinheiro para realizar o cálculo com os números decimais. Segundo esse aluno, 1,4 +1,4 é igual a um real e quarenta centavos mais um real e quarenta centavos é igual a dois reais e oitenta centavos, ou seja, 2,8. Após isso, percebeu-se que esse aluno tentou relacionar a operação com algo do seu cotidiano, de forma que facilitou o seu entendimento e aprendizagem. Essa relação feita pelo aluno enfatiza o que é proposto por Almeida e Costacurta (2010), Santos e Nacarato (2014) e Brasil (2002) sobre a importância da relação da matemática e da geometria com o cotidiano e que, nesse caso, foi feita pelo próprio aluno.

Essa dificuldade com os números decimais pode ter ocorrido devido ao fato de o próprio professor elaborar e explicar problemas com cálculos aproximados, que segundo ele, facilitam quando os alunos irão realizar alguma operação matemática. Porém, deixar de exercitar questões com números decimais, é prejudicial para a aprendizagem do aluno. Isso porque é um conteúdo que está presente na vida cotidiana de qualquer pessoa, como apontado pelo aluno que comparou o cálculo de número decimal com o dinheiro.

Quarta dificuldade: nomeação e explicação sobre as características das figuras geométricas incorretamente

Inicialmente, quando realizada a atividade diagnóstica, alguns alunos chamaram atenção dizendo que não sabiam como explicar a característica das figuras geométricas. De acordo com ele, apenas olhando a figura sabiam fazer a diferenciação. Então para estimular a explicação dos alunos, foram feitos questionamentos além dos que haviam sido propostos. Por exemplo, "porque a figura é um quadrado e não um retângulo?” e "por que não é retângulo e sim paralelogramo?”.

Muitos alunos confundiam a explicação e a nomeação das figuras geométricas. Por exemplo, eles sabiam olhar para um retângulo e dizer que era um retângulo, mas na hora de explicar com suas palavras, eles falavam a característica do quadrado. Além disso, alguns utilizavam os vocábulos geométricos inadequadamente e tinham dificuldades não só na fala, como na escrita das palavras. Por exemplo, o aluno queria falar sobre os lados de uma figura, mas, ao invés de dizer o lado do quadrado, dizia o perímetro do quadrado. Também houve falta de atenção na identificação das unidades medidas do perímetro $(\mathrm{cm})$ e da área $\left(\mathrm{cm}^{2}\right)$.

$\mathrm{Na}$ atividade diagnóstica, os alunos confundiram as características das figuras geométricas. No momento da oficina, através das construções, começaram a entender as diferenças de cada figura e, na entrevista, quando solicitado que explicasse a característica de uma figura, eles sabiam explicar, mas tinham dificuldades em memorizar os nomes dos vocábulos geométricos, como, por exemplo, paralelogramo. 


\section{Considerações finais}

Nesse estudo o ensino da Geometria na EJA não seria apresentado, seria omitido do cronograma de aulas. Após uma conversa entre pesquisadora e professor regente, ele aceitou a proposta em aplicar a oficina de geometria. Ao observar o livro didático utilizado pelo professor regente, percebeu-se uma distribuição dos conteúdos geométricos em três partes: no início, meio e fim. Porém a concentração maior do conteúdo geométrico é no último capítulo do livro, seguindo o que é proposto por Lorenzato (1995) e Pavanelo (1993). Outro fato da omissão do ensino de geometria é devido à falta de preparação e conhecimento do professor em relação aos conteúdos de geometria. Entretanto, o professor regente mostrou-se a vontade para ensinar os conteúdos de geometria, mostrando assim que havia tido conhecimento de geometria.

O objetivo dessa pesquisa foi identificar quais as dificuldades que os alunos da EJA possuem na aprendizagem do cálculo de área e de perímetro das figuras planas. Para isso, foi utilizada uma abordagem qualitativa, cujos procedimentos foram atividade diagnóstica, oficina e entrevista individual com o professor e alguns alunos. A atividade diagnóstica, com o objetivo de identificar o conhecimento prévio dos alunos sobre as figuras geométricas e suas características; a oficina com o objetivo de familiarizar com o material Geoplano, desenvolver o raciocínio para elaborar uma fórmula para calcular o perímetro e a área das figuras planas, diferenciar perímetro de área, memorizar os nomes das figuras geometrias; entrevista com o professor e com alguns alunos com o objetivo de constatar as dificuldades observadas e esclarecer algumas informações.

$\mathrm{Na}$ atividade diagnóstica, a maioria dos alunos conseguiu identificar as figuras geométricas e alguns souberam caracterizar o que as diferem, por exemplo, conseguiram diferenciar um quadrado de um triângulo por meio da explicação escrita. A oficina proporcionou aos alunos, além do conhecimento dos conteúdos geométricos, a experiência de estudar com material manipulativo, o Geoplano, que, de acordo com Almeida e Costacurta (2010) e Fonseca (2011), contribuem para o desenvolvimento do pensamento e da criatividade do aluno. Pois eles estavam acostumados a estudar apenas em sala de aula com metodologias que eram repetidas todos os dias. Isso porque, alguns professores da escola, não utilizam propostas lúdicas de atividades para os alunos. Essas propostas só são utilizadas quando a escola promove alguma atividade envolvendo toda a comunidade escolar.

$\mathrm{Na}$ análise dos dados, as dificuldades foram apresentadas as dificuldades encontradas em cada um dos momentos, e percebeu-se que alguns estiveram presentes em mais de um momento. As dificuldades encontradas em relação à aprendizagem dos alunos foram: a interpretação dos enunciados, o cálculo das quatro operações fundamentais, as operações com os números racionais e decimais e a nomeação e a explicação sobre as características das figuras geométricas incorretamente. 
A partir da análise, também foram encontradas outras dificuldades como: interpretação da escrita realizada pelos alunos, pouco tempo de aula, organização do currículo de matemática e falta de explicação de alguns conteúdos pelo professor. Essas não foram discutidas nesse artigo, pois as dificuldades apresentadas pelos alunos foram o foco.

Apesar das dificuldades encontradas, pode-se perceber que os alunos conseguiram compreender o que é o perímetro e a área de uma figura. Mesmo tendo dificuldade durante a explicação e com o vocabulário geométrico, eles conseguiram mostrar, através do formato retangular do chão da sala que estudam, como calcular o perímetro e a área, mostrando assim a visualização do conteúdo no cotidiano. Para calcular o perímetro, eles iriam somar as medidas das paredes e, para calcular a área, eles iriam medir duas paredes para, posteriormente, multiplicar os valores encontrados. Além disso, associaram o conteúdo aprendido com o cotidiano que vivenciam.

Sendo assim, a presente pesquisa traz subsídios para os professores aprofundarem o ensino de Geometria na EJA, exercitar o vocabulário geométrico nas aulas de formação de professores e trabalhar as dificuldades que os professores encontram na aprendizagem dos alunos em relação aos conteúdos de Geometria, na tentativa de sanar as dificuldades.

Além disso, poderá oportunizar uma ampliação da discussão de uma temática ainda insipiente no âmbito da Educação Matemática, bem como gerar reflexões para as práticas formativas e suas implicações para aprendizagem da Geometria no contexto da EJA, e também, poderá contribuir para que outras pesquisas sejam realizadas na área.

Ao término da pesquisa, ainda ficaram alguns questionamentos: Quais os recursos que podem ser utilizados para diminuir essas dificuldades de aprendizagem dos alunos da EJA nos conteúdos de Geometria? Modelagem Matemática, História da Matemática, Etnomatemática, Resolução de Problemas, Tecnologias Digitais, quais dessas tendências contribuiriam para a aprendizagem? Cursos de aperfeiçoamento para os professores seriam suficientes para diminuir essas dificuldades dos alunos da EJA? A utilização de materiais e recursos manipuláveis contribui para a aprendizagem em Geometria na EJA? Talvez as respostas dessas perguntas possam contribuir para a aprendizagem dos alunos e também para a formação dos professores de Matemática.

\section{Referências}

AlmeidA, D. C. C. de; COSTACURTA, M. S. Atividades lúdicas para o ensino e aprendizagem da geometria nos anos finais do ensino fundamental. Chapecó (2010). Disponível em: <https://www.unochapeco.edu.br/publicacoescientificas/detalhes/>. Consultado em: 10 fev. 2017.

BODGAN, R. C; BIKLEN, S. K. Investigação qualitativa em educação: uma introdução à teoria e os métodos. Portugal: Porto Editora, 1994. 
BRASIL. Educação para Jovens e Adultos: Ensino Fundamental: Proposta Curricular - $1^{\circ}$ Segmento. $3^{\text {a }}$ ed. Vera Maria Masagão Ribeiro. (Coord.). São Paulo: Ação Educativa; Brasília: MEC, 2001.

- Proposta Curricular para a Educação de Jovens e Adultos: segundo segmento do ensino fundamental $-5^{\mathbf{a}}$ a $8^{\mathbf{a}}$ série. Brasília: Ministério da Educação e Cultura (MEC) /Secretaria de Educação Fundamental (SEF), v.3, 2002.

Lei no 9.394, de 20 de dezembro de 1996. Estabelece as diretrizes e bases da educação nacional. Disponível em: < http://www.planalto.gov.br/ccivil_03/Leis/L9394.htm>. Acesso em: 15 jan. 2015.

FONSECA, M. da C. F. R. Educação matemática de jovens e adultos: discurso, significação e constituição de sujeitos nas situações de ensino aprendizagem escolares. In: SOARES, Leôncio; GIOVANETTI, M. A.; GOMES, N. L. (Orgs.). Diálogos na educação de jovens e adultos. Belo Horizonte: Autêntica, p. 225-240, 2011.

. Maria da Conceição Ferreira Reis; et.al. O ensino de Geometria na Escola Fundamental: três questões para a formação do professor dos ciclos iniciais. Belo Horizonte: Autêntica, ed. 3, 2009.

FIORENTINI, D.; LORENZATO, S. Investigação em Educação Matemática-percursos teóricos e metodológicos. 3. ed. Campinas - São Paulo: Autores associados. 2009. LORENZATO, S. Porque não ensinar Geometria?. A Educação Matemática em Revista SBEM, $n^{\circ} 4,1995$.

LÜDKE, M.; A., M. E. D. A. de. Pesquisa em Educação: Abordagens Qualitativas. Rio de Janeiro: EPU, ed. $2^{\mathrm{a}}, 2013$.

PAVANELlO, R. M. O abandono do ensino da geometria no Brasil: causas e conseqüências. Revista Zetetiké, São Paulo: ano 1, nº 1, p. 07-17, 1993.

SANTOS, Cleane Aparecida dos; NACARATO, Adair Mendes. Aprendizagem da Geometria na educação básica: a fotografia e a escrita na sala de aula. 1 ed. Belo Horizonte: Autêntica, 2014.

SCRIVANO, C. N. et al. Ciência, transformação e cotidiano: ciências da natureza e matemática ensino médio: Educação de Jovens e Adultos. Coleção viver, aprender. 1. ed. - São Paulo: Global, 2013.

\section{Biografia Resumida}

Taiane de Oliveira Rocha: Graduada em Licenciatura em Matemática pela Universidade Estadual do Sudoeste da Bahia (UESB), Mestranda do Programa de Pós-Graduação em Ensino ISSN 2526-2882 
Integrante do Grupo de Pesquisa e Extensão em Tecnologias Digitais no Ensino -GPETDEN. Integrante do Grupo de Articulação, Investigação e Pesquisa em Educação Matemática GAIPEM

Lattes: http://lattes.cnpq.br/7379756370857145

Contato: taiane.o.r@gmail.com

Jonson Ney Dias da Silva: Graduado Licenciatura em Matemática - UEFS, Mestre em Ensino, Filosofia e História das Ciências UFBA, Universidade Estadual do Sudoeste da Bahia, Doutorando do Programa de Pós-Graduação em Educação Matemática da Universidade Estadual Paulista "Júlio de Mesquita Filho" (UNESP)/Rio Claro, Líder do Grupo de Articulação, Investigação e Pesquisa em Educação Matemática - GAIPEM, Integrante do Grupo de Pesquisa em Informática, outras Mídias e Educação Matemática-GPIMEM

Lattes: http://lattes.cnpq.br/3428538345974180

Contato: jonsonney@yahoo.com.br 